
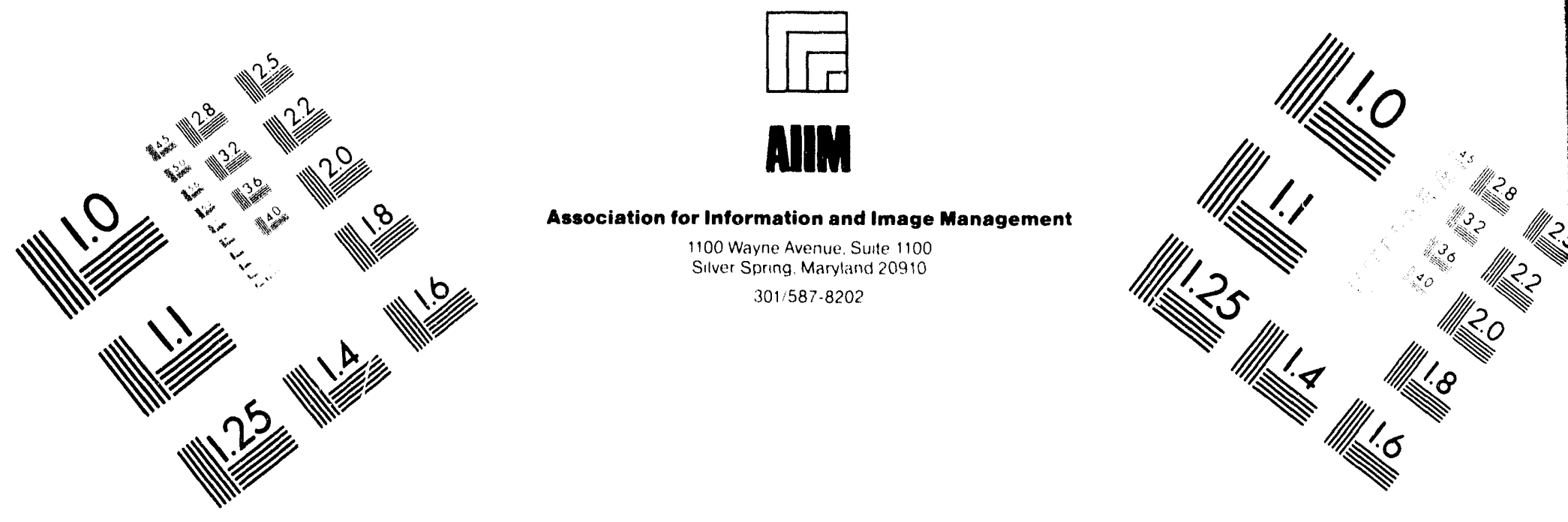

\title{
Centimeter
}

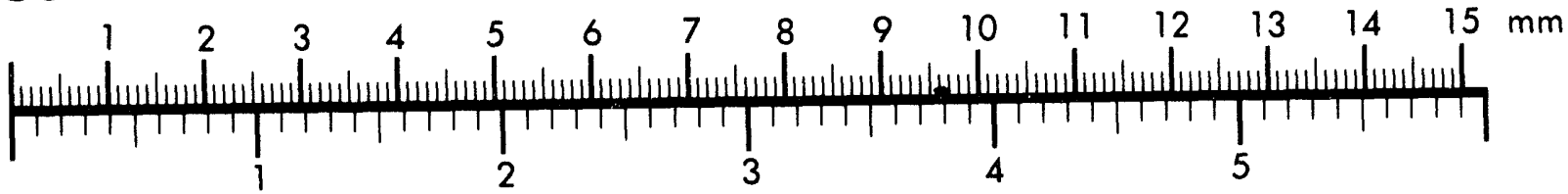
Inches
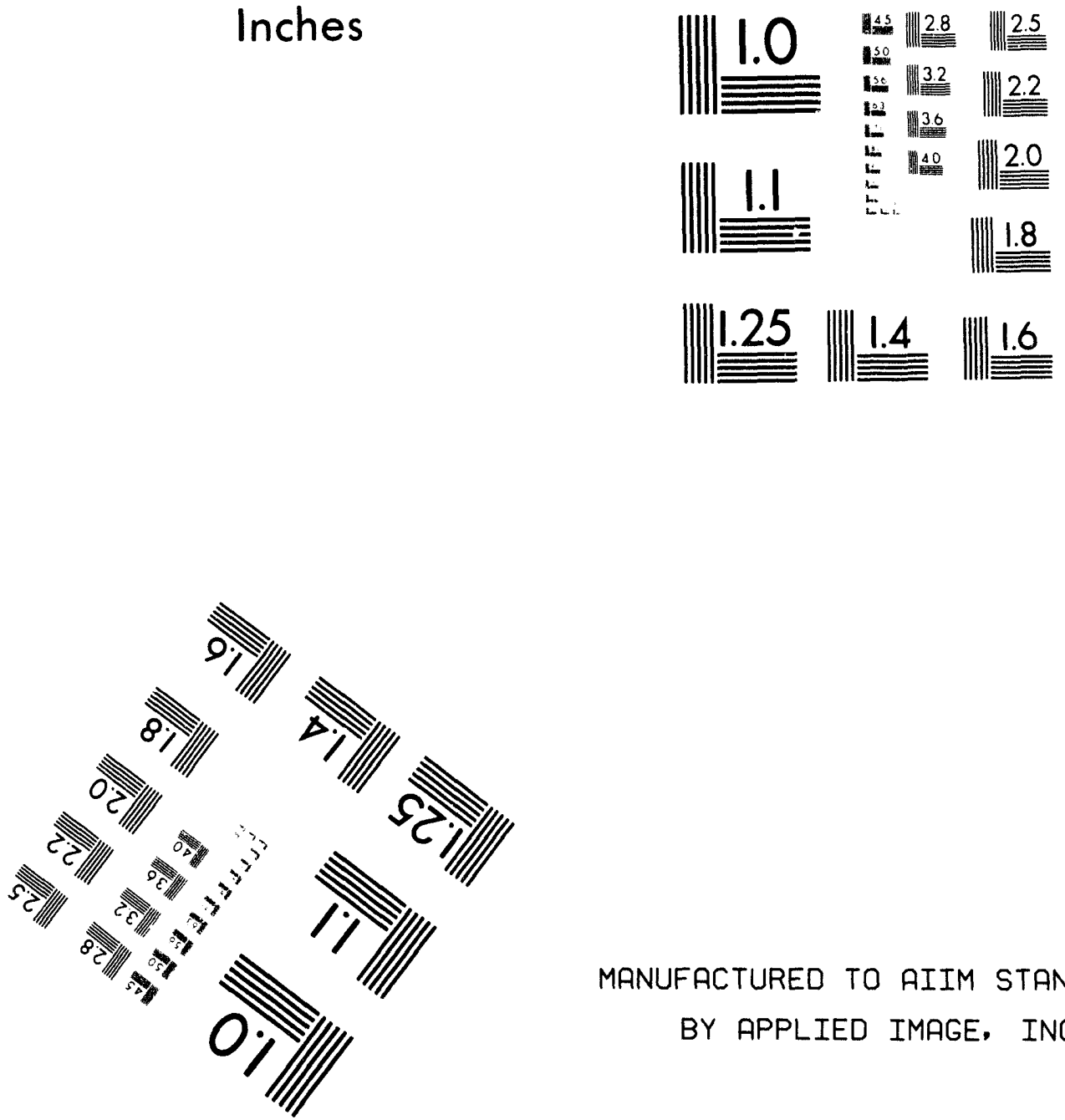

MANUFACTURED TO AIIM STANDARDS

BY APPLIED IMAGE, INC.

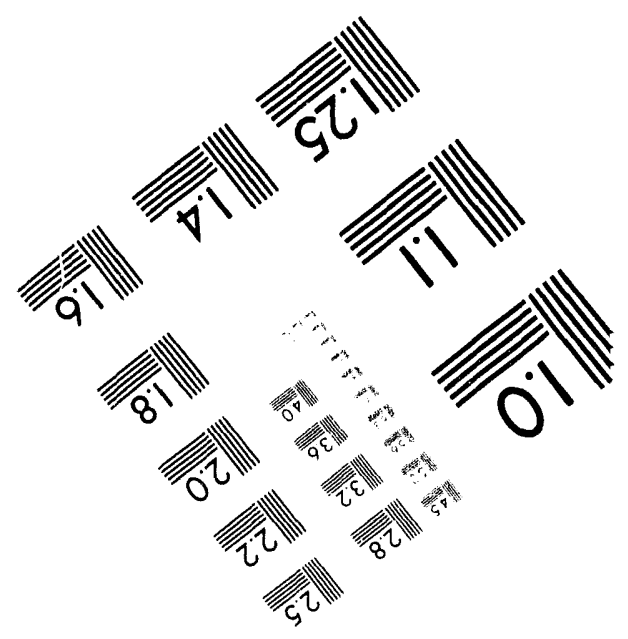



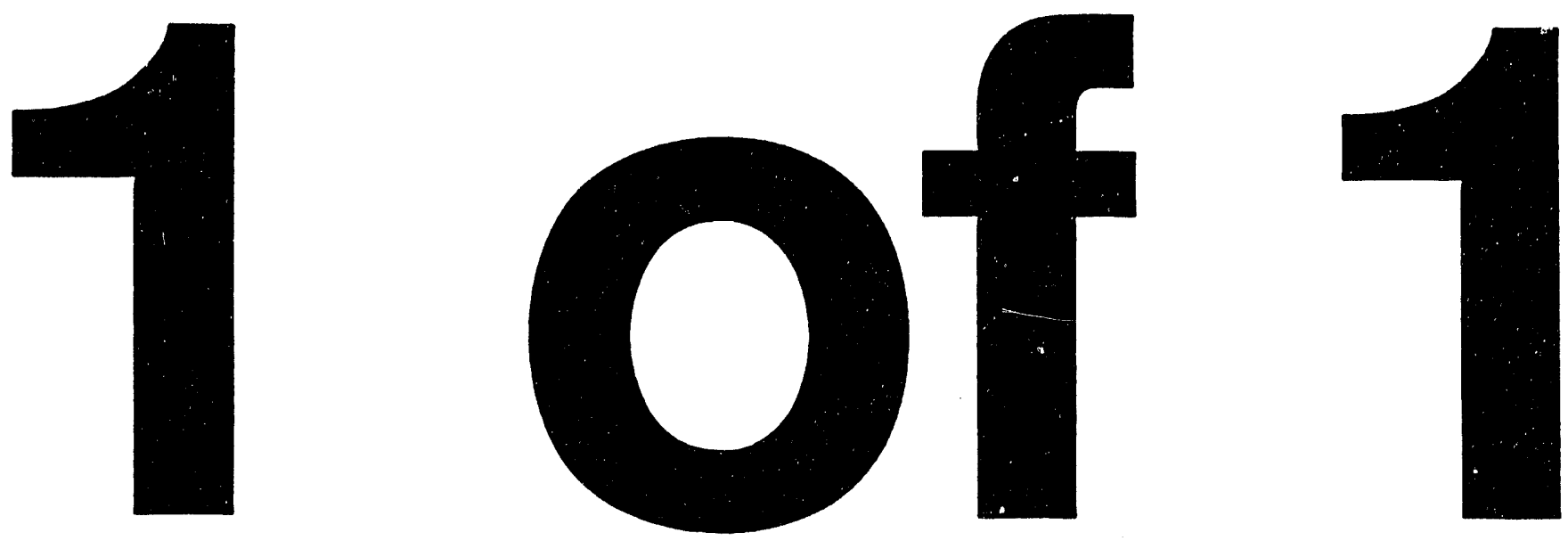


\section{WVNS Tank Farm Process Support \\ Performance Evaluation of Corrosion Probes in Simulated WVNS Tank 8D-2 Waste}

M. R. Elmore

July 1994

Prepared for West Valley Nuclear Services and the U.S. Department of Energy under Contract DE-AC06-76RLO 1830

Pacific Northwest Laboratory Richland, Washington 99352 


\section{Summary}

Five corrosion probes were received from West Valley Nuclear Services for evaluation in simulated tank 8D-2 3rd-stage sludge wash slurry. The same waste slurry simulant was also used in a series of ongoing corrosion studies assessing the effects of in-tank sludge washing on the integrity of tank 8D-2. Two of the corrosion probes were installed in the coupon corrosion test vessels operating at $\sim 150^{\circ} \mathrm{F}$ to compare performance of the probes with that observed by coupon tests conducted in the same vessels.

Corrosion rate data calculated from electrical resistance measurements of the corrosion probes were evaluated for this study using two slightly different approaches. One approach uses the total length of exposure of the probe to give a "time-averaged" value of the corrosion rate. The other approach uses a shorter period of time (relative to the length of the test) in the calculation of corrosion rate, and is referred to as the "instantaneous" rate. The interpretation of the probe data and the implications of corrosion rates calculated with either of these methods are discussed in this report.

Corrosion rates indicated by the probes have steadily decreased over the approximately 6 months of exposure. Time-averaged corrosion rates have decreased from initial high readings of $\sim 2$ mils per year (mpy) in the vapor space and $\sim 1$ mpy submerged in the simulant to values of $\sim 0.4 \mathrm{mpy}$ (vapor space) and $\sim 0.1 \mathrm{mpy}$ (submerged). These results agree reasonably well with uniform corrosion rates calculated from corrosion coupon data after similar exposure times.

Instantaneous corrosion rates indicated by the probes are similar to the timeaveraged values early in the test. Toward the end of the test, both vapor space and submerged instantaneous rates are essentially zero, since the higher initial rates are not factored into the calculation like the time-averaged results.

Pitting was expected to occur on the vapor-space probe (as on the vapor-space coupons), which should have significantly increased the electrical resistance-determined corrosion rates. The vapor space probe element was heavily encrusted with corrosion products like the coupons, but the probe was not acid-cleaned after the test as were the coupons. Therefore, pitting was not directly observed. The calculated corrosion rates were also consistent with the coupon rates for uniform corrosion.

Since pitting did not lead to premature failure of the vapor space probe, and since the probe rates agreed reasonably well with the coupon test results, the resistance-type corrosion probes appear to be useful indicators of tank corrosion rates. It is recommended that monitoring of the resistance probes in tank 8D-2 continue, and that laboratory evaluation of the probes continue as part of the simulated sludge wash corrosion testing. 


\section{Contents}

Summary $\ldots \ldots \ldots \ldots \ldots \ldots \ldots \ldots \ldots \ldots \ldots \ldots \ldots \ldots \ldots \ldots \ldots \ldots \ldots$

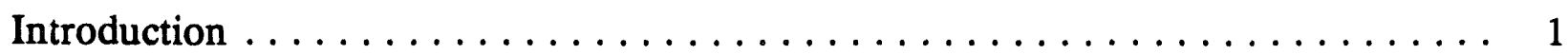

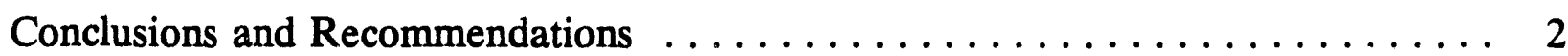

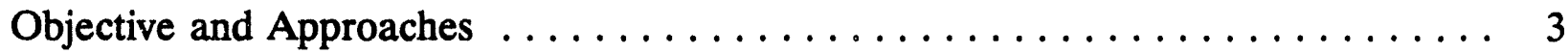

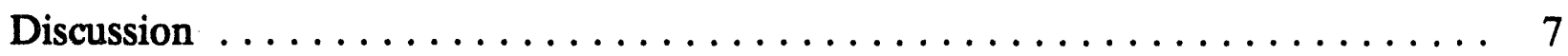




\section{Figures}

1 Sketch of Resistance-Type Corrosion Probe Evaluated in the Study . . . . . 4

2 Hypothetical Graph of Observed Corrosion Rates Comparing

"Time-Averaged" and "Instantaneous" Curves ................ 6

3 Vapor Space Corrosion Probe Results Compared With Coupon

Test Results at the Same Time $\ldots \ldots \ldots \ldots \ldots \ldots \ldots \ldots \ldots$

$4 \quad$ Submerged Corrosion Probe Results Compared With Coupon

Test Results . . . . . . . . . . . . . . . . . . . . . . . . 8

\section{Table}

1 Target Composition of Tank 8D-2 3rd-Stage Wash Stimulant $\ldots \ldots \ldots \ldots$ 


\section{Introduction}

Radioactive waste slurries resulting from spent fuel reprocessing operations at West Valley Nuclear Services (WVNS), West Valley, New York, have been stored in carbon steel underground storage tanks. During planned disposal operations at WVNS, the settled sludge in storage tank 8D-2 will be retrieved, pretreated, and vitrified. Prior to retrieval and vitrification, however, the sludge must be washed to reduce the concentration of soluble sulfates in the waste.

Corrosion of the carbon steel waste storage tanks at WVNS continues to be of concern, especially as the planned duration of waste storage time increases and sludge washing operations are conducted. Corrosion of carbon steel in aqueous environments has been extensively studied. However, in the particular environment of tank 8D-2, there is insufficient knowledge of specific corrosion mechanisms and corrosion rates as functions of various influencing parameters [e.g., system geometry, temperature, radiolysis, $\mathrm{pH},\left(\mathrm{NO}_{3}{ }^{-}\right),\left(\mathrm{NO}_{2}{ }^{-}\right)$, etc.].

Corrosion testing is being conducted at the Pacific Northwest Laboratory ${ }^{(a)}$ with carbon steel coupons in simulated tank 8D-2 waste to assess potential corrosion mechanisms and estimate corrosion rates in the tank for the duration of the sludge washing campaign. Corrosion probes are also being investigated as a means of measuring corrosion rates directly in the tank over the remainder of its life. To evaluate the performance of the electrical resistance-type corrosion probes, tests are being performed with the probes in conjunction with the simulated waste/corrosion coupon tests. This direct comparison (corrosion coupon results vs. probe readings) provides a basis for validating results of similar probe readings taken in tank 8D-2.

(a) Facific Northwest Laboratory is operated by Battelle Memorial Institute for the U.S. Department of Energy under Contract DE-AC06-76RLO 1830. 


\section{Conclusions and Recommendations}

Resistance-type corrosion probes supplied by WVNS were evaluated in simulated tank 8D-2 3rd-stage sludge wash slurry and in the vapor space above the simulant at $150^{\circ} \mathrm{F}$ for approximately 6 months. Corrosion rates determined by the probes were compared to uniform corrosion rates calculated from the coupon tests at the same conditions. The following conclusions can be drawn from this investigation:

- Vapor-space corrosion-probe corrosion rates (time-averaged) agree reasonably well with comparable results from the coupon tests for the same exposure [less than 1 mil per year (mpy) for the coupons vs. 0.3 mpy for the probe].

- Submerged corrosion-probe corrosion rates (time-averaged) agree reasonably well with comparable results from the coupon tests for the same exposure [less than 0.1 mil per year (mpy) for the coupons vs. $\sim 0.15 \mathrm{mpy}$ for the probe]. These rates are essentially insignificant in terms of tank corrosion.

- Pitting was expected to occur on the vapor space probe element (as with the vapor space coupons). The element was heavily encrusted with corrosion products, and the scale was not removed after the test by cleaning with inhibited acid. Therefore, pitting was not directly observed on the vapor space probe element. It is assumed that pitting did not significantly affect the results of the probe, since results agreed reasonably well with the coupon results. Therefore, it is concluded that the resistance-type probes can be used to indicate the uniform corrosion rates occurring in tank 8D-2 (vapor space and submerged) under conditions similar to those of these tests.

The following recommendations are made based on the results of the laboratory evaluation of the resistance-type corrosion probes in simulated tank 8D-2 slurry:

- It is recommended that monitoring of tank $8 \mathrm{D}-2$ environment with the presently installed resistance-type corrosion probes be continued. Results may differ somewhat between the probes in tank 8D-2 and the simulant test probes. However, generally good agreement was observed between test probe results and corrosion coupon results, indicating the suitability of this type of probe for the tank environment. Any differences in results of the tank probes compared to the simulant test probes are probably due to differences in waste vs. simulant chemistry.

- It is also recommended that laboratory testing of the probes in simulated waste slurry be continued in conjunction with the planned (THOREX addition) 4thstage sludge wash corrosion tests. 


\section{Objective and Approaches}

The objective of the corrosion probe tests described by this report was to compare the performance of the probes with corrosion rates observed on carbon steel coupons of similar material exposed to the same simulated waste slurry environment. This comparison is needed to help validate the result of resistance-type corrosion probes presently operating in tank 8D-2. This evaluation also helps to establish the suitability of future testing with corrosion probes in similar environments.

Five corrosion probes were received from WVNS in February, 1993. The probes are resistance-type corrosion probes manufactured by Rohrback-Cosasco Systems in Santa Fe Springs, California. The resistance elements of the probes were manufactured in all cases from an alloy similar to the mild steel used to fabricate tank 8D-2 (Rohrback describes the probe material as a "nominal 1018 mild steel"). A similar material is being used in the coupon corrosion tests (ASTM A-516 grade 55). A portable "corrosion meter" for reading the probes (a "Corrosometer" obtained from Rohrback Cosasco) was also supplied by WVNS. Figure 1 is a sketch of the resistance-type corrosion probe. Note that the resistance element is protected from physical damage by a heavy but perforated guard surrounding the U-shaped element at the end of the probe.

In operation, the resistance element is exposed to the environment of interest (in this case the simulated waste slurry and the vapor space above the waste simulant). As corrosion of the sensing element occurs, its cross section is reduced, increasing the electrical resistance across the probe. By using an appropriate sensing instrument, the increase in resistance as the probe corrodes can be converted into a metal loss rate.

To minimize error in the resistance readings, a secondary resistance element is built into each probe. This resistor is sealed from the corrosion environment, but is at essentially the same temperature as the test element. Each time resistance readings are taken, the secondary "check" resistor is also measured. With the "check" element built into the probe, variations in test temperature, poor electrical connections to the Corrosometer, and other factors that may contribute to differences in measured electrical resistance readings other than resistance of the test element itself are detected by changes in the "check" reading.

The simulated waste slurry used in the corrosion tests was prepared by "washing" a simulated tank 8D-2 waste sludge to yield a slurry matching an estimate of the composition of tank 8D-2 slurry resulting from three "sludge wash" cycles. The composition of the simulant was specified by WVNS staff prior to initiating the 3rd-stage sludge wash coupon tests. Major components of the waste simulant are shown in Table 1. 


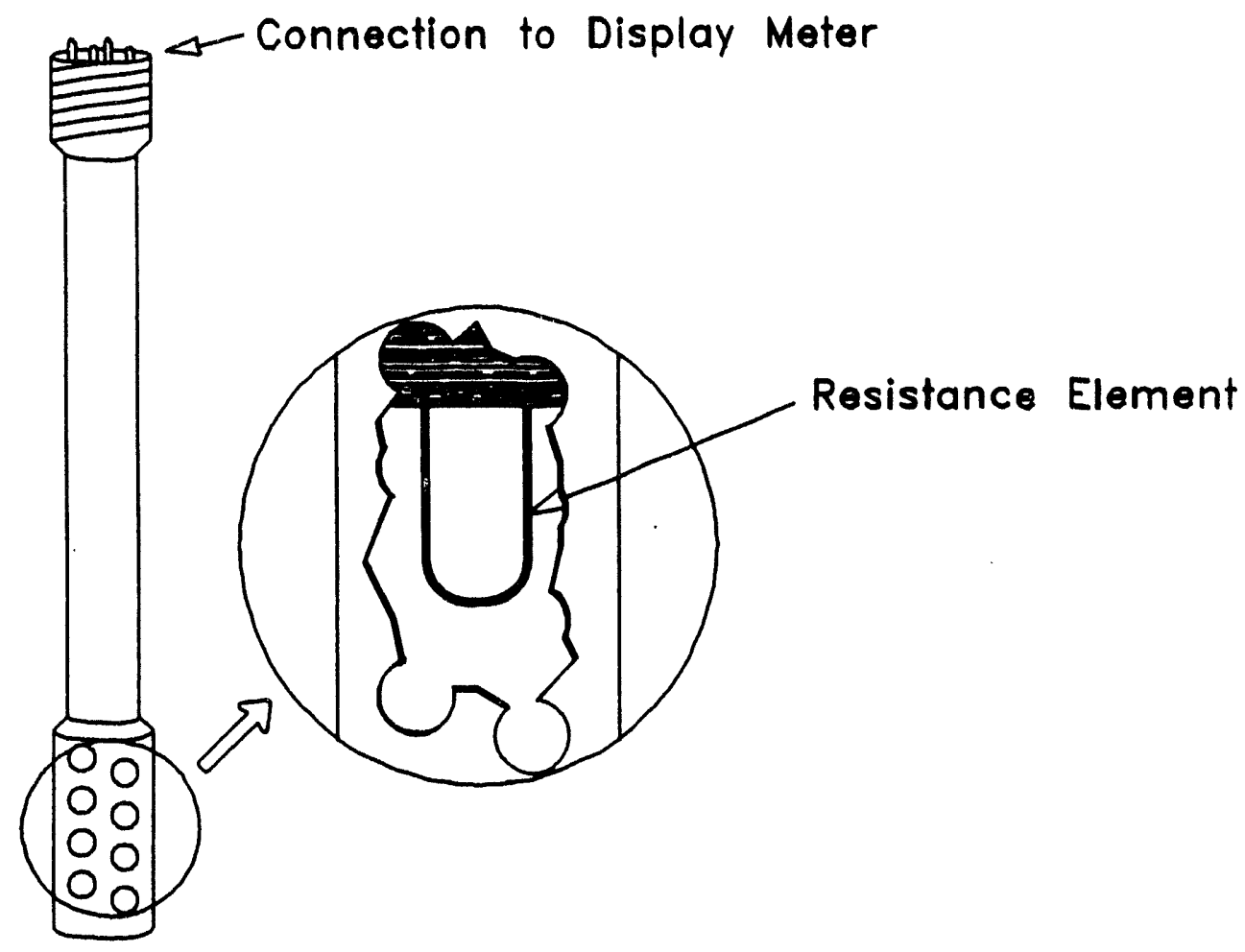

Figure 1. Sketch of Resistance-Type Corrosion Probe Evaluated in this Study. Note the U-shaped element whose electrical resistance increases as corrosion proceeds.

Table 1. Target Composition of Tank 8D-2 3rd-Stage Wash Simulant

\begin{tabular}{lr} 
Component & 5900 \\
\cline { 2 - 2 } Nitrate & 4700 \\
Nitrite & 1900 \\
Sulfate & 80 \\
Chloride & $\begin{array}{c}\text { Concentration } \\
\text { (ppm) }\end{array}$ \\
Hydroxide & $\mathrm{pH}>12$
\end{tabular}


Not knowing how the probes might react in the tests, and anticipating that the probes could be useful in future testing to help better define corrosion inhibition chemistry, it was decided to evaluate just two of the five probes at first. Both probes were placed in the vessels being held at $\sim 150^{\circ} \mathrm{F}$. One probe was placed in each of two duplicate vessels. (One probe was situated so that the sensing element was submerged in the slurry simulant in the vessel, and the other probe so that the sensing element was suspended in the vapor space of the vessel.)

Resistance-type corrosion probes provide corrosion data by correlating changes in electrical resistance of the probes with corrosion of the sensing element. Corrosion rates are determined by measuring the change in resistance over a particular period of time. This time frame may include the entire length of exposure back to the time the probe was first exposed to the corroding environment, and is referred to in this report as a "time-averaged" value. The time-averaged rate includes the effects of relatively higher corrosion rates observed when a new probe is first exposed to the test environment.

Alternatively, the time frame for the corrosion rate calculation may be relatively short compared to the total length of exposure. In this case, a short interval next to the point of interest can be used to give a calculated corrosion rate that is probably closer to the actual corrosion rate at that time. This method is referred to in this report as the "instantaneous" rate. The advantage of this approach is that the readings more closely reflect corrosion happening to the tank at that time. A disadvantage of this approach is that the effects of using a short interval of time in the calculation magnify the uncertainties involved in measuring the very small changes in electrical resistance that occurs over the short time.

Both of these approaches to corrosion rate measurements are illustrated in Figure 2. Note that an initial period, referred to as an "induction period," is typical of a new probe. The clean surface of the resistance element is unprotected by a passivating oxide layer, and the corrosion rate observed in this region is quite high compared to later times. As time proceeds, an oxide film accumulates and lowers the measured corrosion rate to a more constant value. This is referred to as the "stabilized" region where corrosion proceeds at a more constant rate.

The differences in corrosion rates illustrated by the two curves in Figure 2 ("timeaveraged" and "instantaneous") result from the inclusion or exclusion, respectively, of larger changes in electrical resistance (i.e., high corrosion rates) occurring during the early induction period in the corrosion rate calculation. 
i

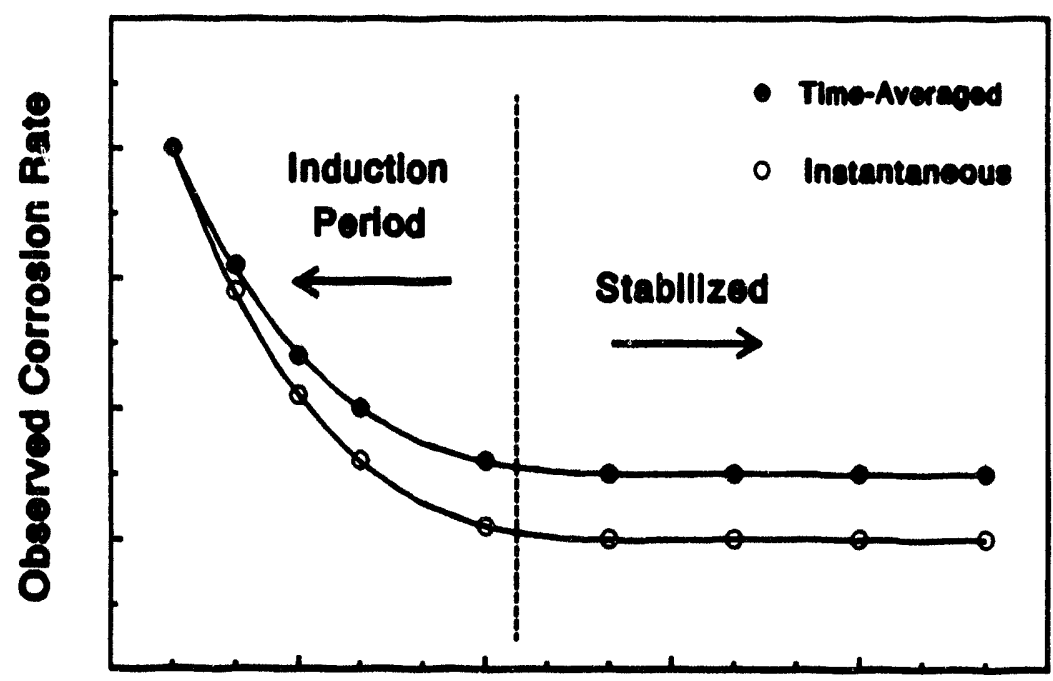

Exposure TIme

Figure 2. Hypothetical Graph of Observed Corrosion Rates Comparing "Time-Averaged" and "Instantaneous" Curves

The formula for calculating corrosion rate from the resistance readings of the probe is shown below:

$$
\text { Corrosion Rate (mpy) }=\frac{\text { Change in Reading }}{\text { Days of Exposure }} \times 0.365 \times \text { SPAN }
$$

where SPAN $=4$ for the specific probes being evaluated in this study. "Days of Exposure" can be any time interval over which the "Change in Reading" is measured. 


\section{Discussion}

Resistance readings were made periodically throughout the duration of the probe evaluation. Corrosion rates were then calculated from these readings by the formula shown above. Figures 3 and 4 show the corrosion rates calculated from the probe resistance readings as a function of time over the $\sim 6$ months exposure to the simulated waste slurry. The corrosion rates in Figure 3 are for the vapor space probe. Results were determined and are presented in the two ways, described in the preceding section: 1) "time-averaged" (comparable in principle with the method used to determine corrosion rates from coupon weight loss measurements), and 2) "instantaneous," which does not include the resistance changes that occurred during the initial period. The coupon corrosion rates (time-averaged) are also shown for comparison.

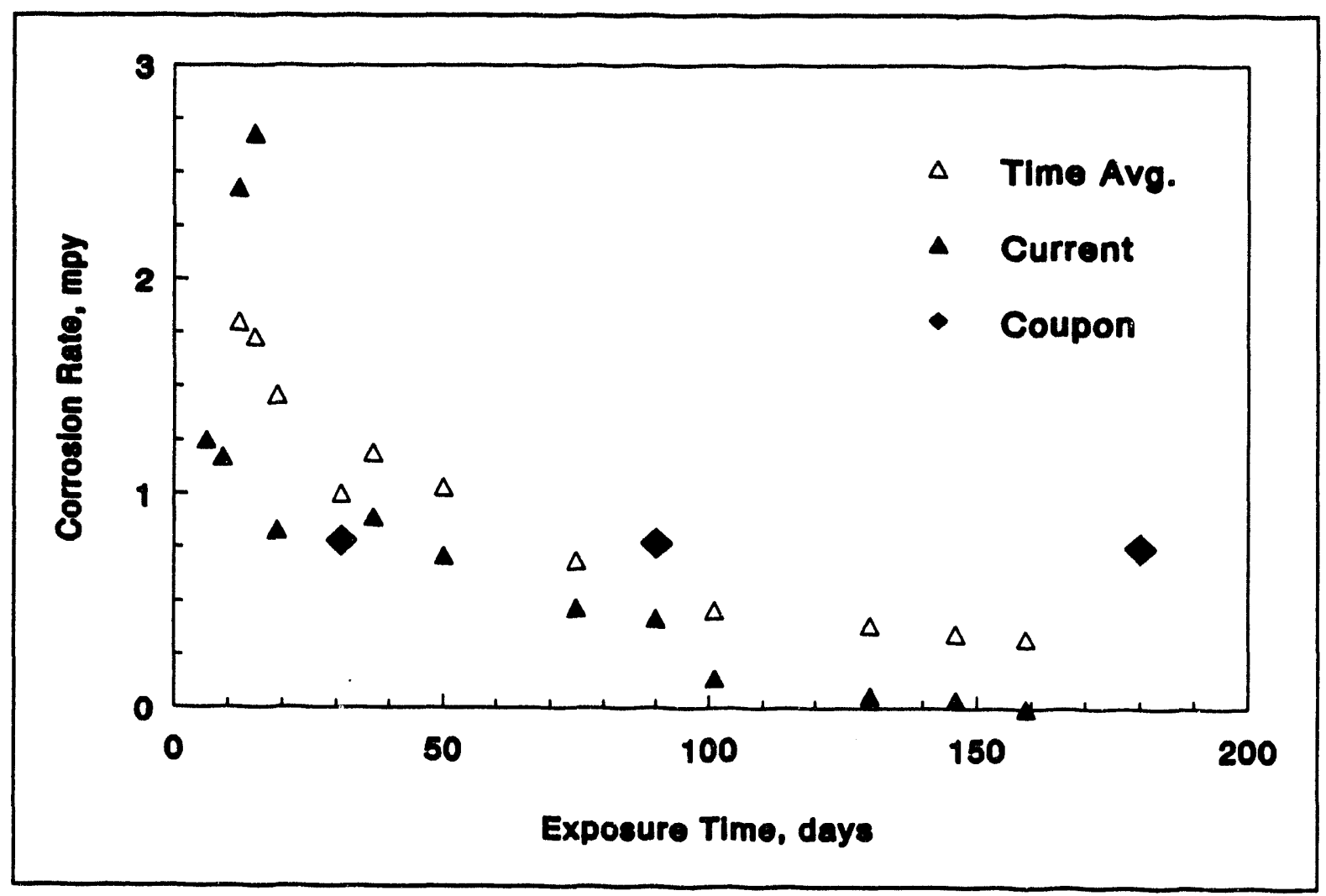

Figure 3. Vapor Space Corrosion Probe Results Compared With Coupon Test Results At Same Conditions 


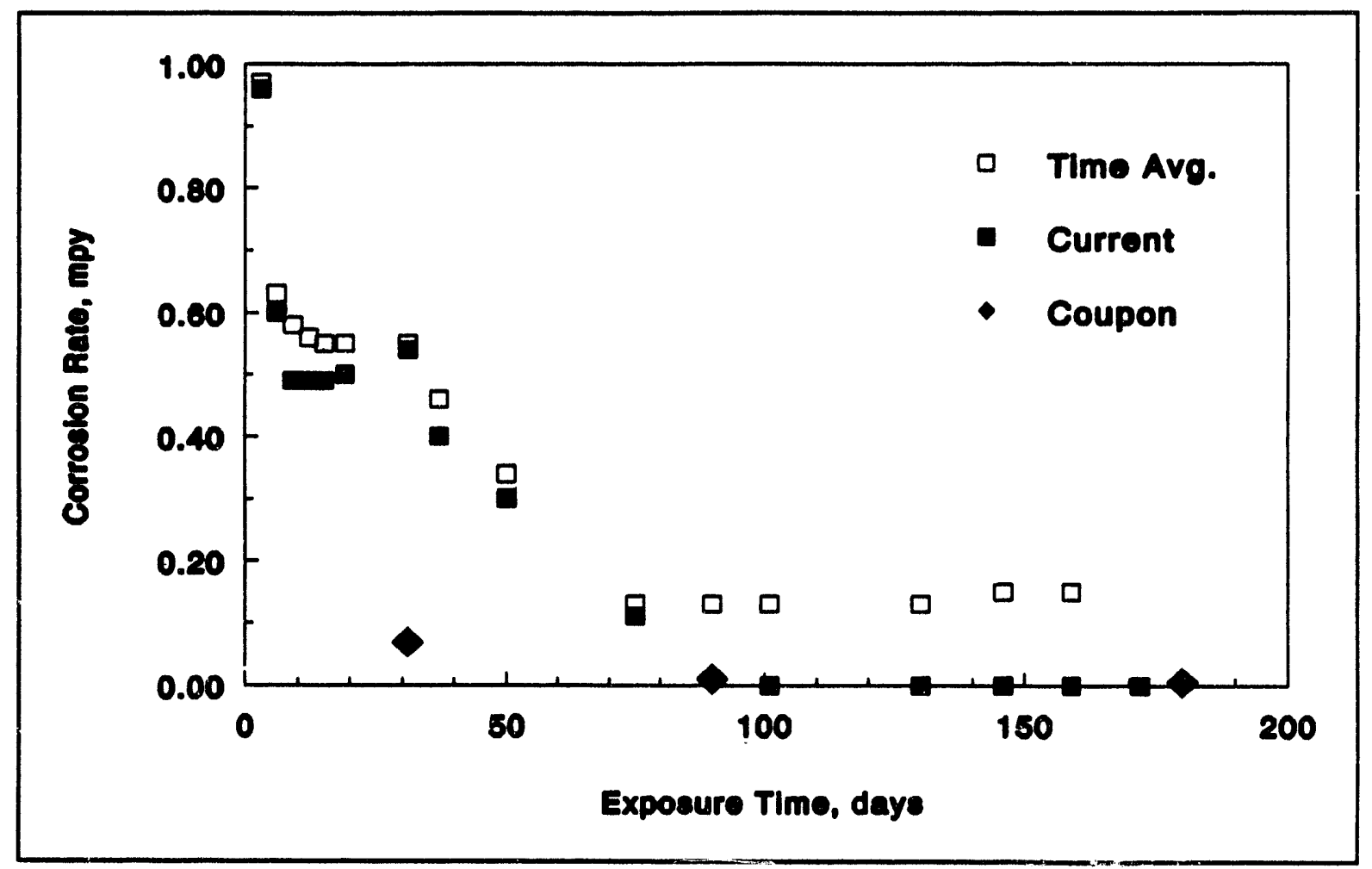

Figure 4. Submerged Corrosion Probe Results Compared With Coupon Test Results

Corrosion rates decrease over time from initially high values to lower "steadystate" values after $\sim 100$ days of exposure. This 100-day induction period is apparently necessary for the probe to stabilize with its environment at these conditions, and may vary with different environments. During these first $\sim 100$ days, the corrosion rates experienced by the probe are somewhat higher than those seen by the tank during the same period, which is assumed to be due to the initial lack of protective oxide film on the probe element. Longer-term exposure "instantaneous" corrosion rates decrease to essentially zero, while the time-averaged rates are slightly higher.

In Figure 4, the probe corrosion rates shown (time-averaged and instantaneous) are for the submerged probe. Time-averaged results for submerged coupons are included for comparison. Again, instantaneous corrosion rates decrease from initially higher values to essentially zero after 100 days, while the time-averaged values are also very low but somewhat higher.

Based on the results of the probe evaluations, it appears that the corrosion probes can provide meaningful, real-time estimates of the corrosion rates at different locations within the waste tank 8D-2. The term "estimate" is used because it must be assumed that corrosion is occurring uniformly over the surfaces of the test elements of the probes. 
It is seen from the coupon tests that some of the metal loss, especially in the vapor space above the simulant, is due to pitting corrosion. However, it is likely that because of the near real-time nature of the resistance measurement, the corrosion probes would be capable of detecting abrupt changes to corrosion rates in the tank caused by changes to the waste chemistry. Corrosion coupons do not readily provide this type of near realtime capability, and in the radioactive environment, corrosion coupons are difficult to test and evaluate. 


\section{Distribution}

No. of

Copies

Offsite

$2 \quad$ U.S. Department of Energy Officis of Scientific and

Technical Information

2 West Valley Nuclear Services Rock Springs Road

P.O. Box 191

West Valley, NY 14171-0191

Ji Young Chang

Dan C. Meess
No. of

Copies

$\underline{\text { Onsite }}$

9 Pacific Northwest Laboratory

W.F. Bonner, P7-41

R.E. Westerman, P8-44

M.R. Elmore, P8-30

Publishing Coordination

Technical Report Files, (5) 

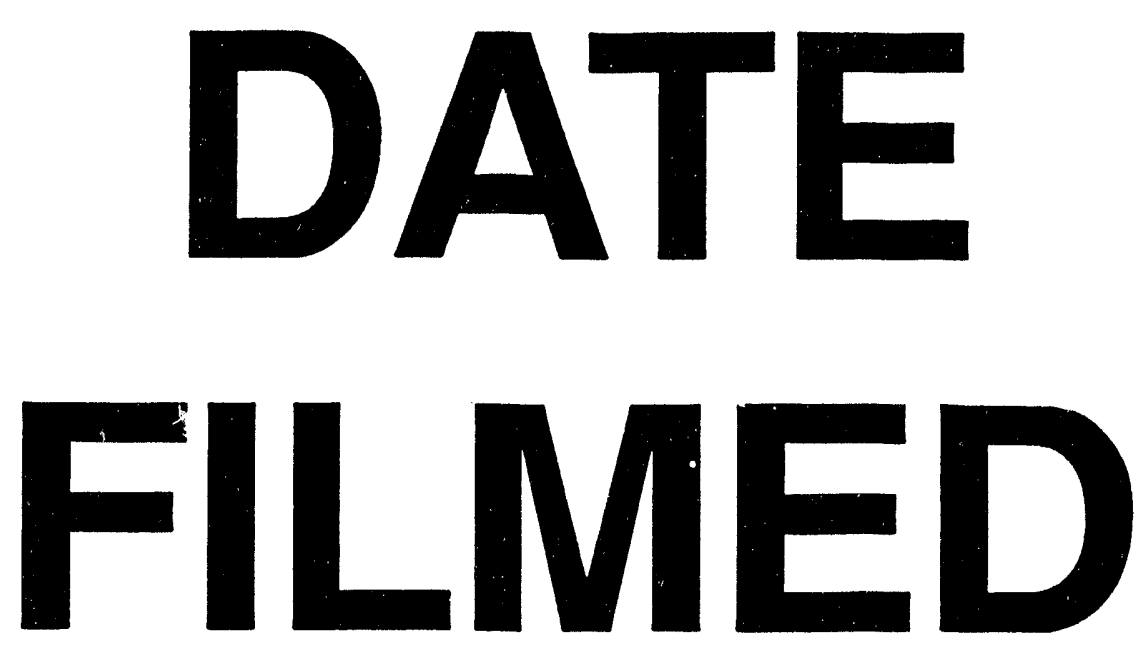

$11 / 2 / 94$
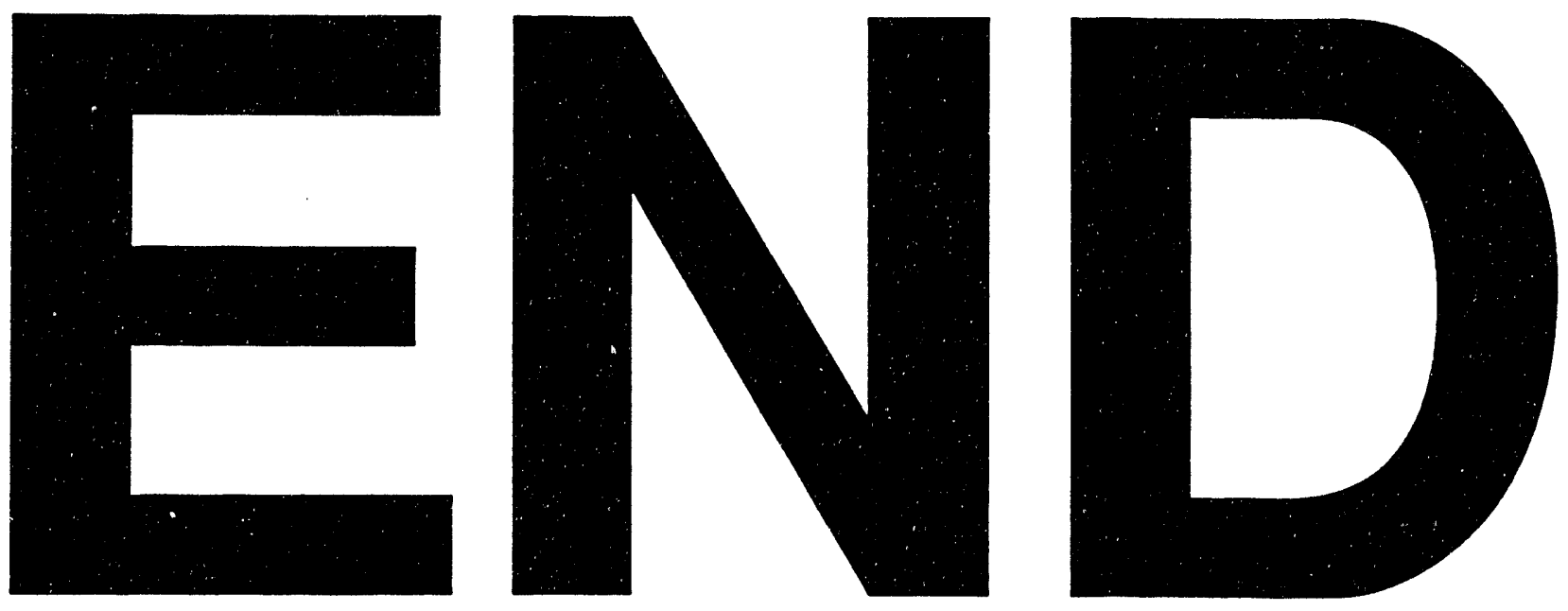
